\title{
Combinatorial Physics
}




\section{SERIES ON KNOTS AND EVERYTHING}

Editor-in-charge: Louis H. Kauffman

\section{Published:}

Vol. 1: Knots and Physics

L $H$. Kauffman

Vol. 2: How Surfaces Intersect in Space

J. S. Carter

Vol. 3: Quantum Topology edited by L. H. Kauffman \& R. A. Baadhio

Vol. 4: Gauge Fields, Knots and Gravity

J. Baez \& J. P. Muniain

Vol. 6: Knots and Applications edited by $L . H$. Kauffman

Vol. 7: Random Knotting and Linking edited by $K$. C. Millett \& D.W. Sumners

Vol. 10: Nonstandard Logics and Nonstandard Metrics in Physics W. M. Honig

Forthcoming:

Vol. 5: Gems, Computers and Attractors for 3-Manifolds S. Lins

Vol. 8: Symmetric Bends: How to Join Two Lengths of Cord R. E. Miles 
81 Series on Knots and Everything - Vol. 9

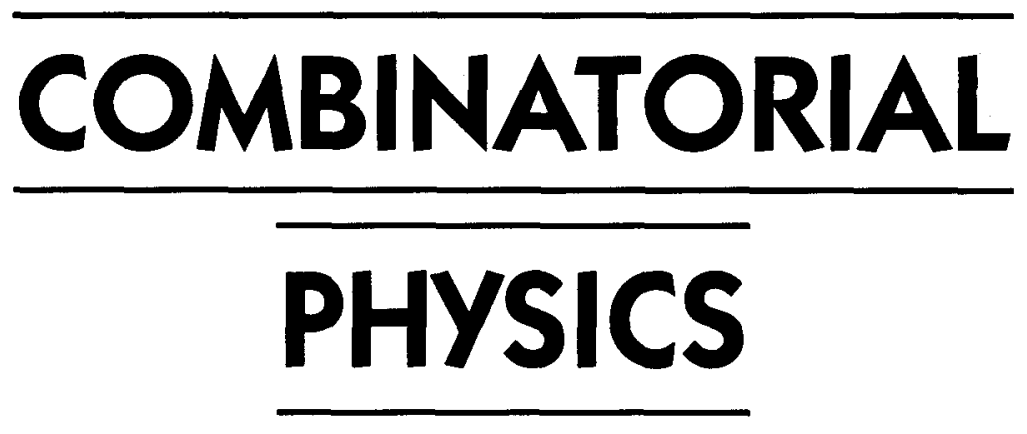

\section{T Bastin \\ C W Kilmister}




\section{Published by}

World Scientific Publishing Co. Pte. Ltd.

P O Box 128, Farrer Road, Singapore 9128

USA office: Suite 1B, 1060 Main Street, River Edge, NJ 07661

UK office: 57 Shelton Street, Covent Garden, London WC2H 9HE

\section{COMBINATORIAL PHYSICS}

Copyright 1995 by World Scientific Publishing Co. Pte. Ltd.

All rights reserved. This book, or parts thereof, may not be reproduced in any form or by any means, electronic or mechanical, including photocopying, recording or any information storage and retrieval system now known or to be invented, without written permission from the Publisher.

For photocopying of material in this volume, please pay a copying fee through the Copyright Clearance Center, Inc., 222 Rosewood Drive, Danvers, Massachusetts 01923, USA

ISBN 981-02-2212-2

This book is printed on acid-free paper.

Printed in Singapore by Uto-Print 


\section{Preface}

It is nearly fifty years since the authors of this book began a collaboration based on their common interest in the foundations of physics. During that time others have made very major contributions. The fruits of this cooperative enterprise, particularly of the later part of it, are set out here. One problem has led to another. Over that time it became clear that such existing preconceptions as the space and time continua formed an inadequate basis for a physics which has to incorporate a quantum world of discrete character. Here we argue that the impossibility of reconciliation between continuous and discrete starting points means that we must start from the discrete or combinatorial position. Otherwise the quantum theory will remain with confusion and muddle at its centre.

If intuitive clarity is to come from the combinatorial approach it turns out to be hard won because continuum ideas are so deeply embedded in orthodox physics. It has been possible to travel only part of the way but that has been far enough to reveal another positive aspect of the approach. Discreteness is intimately related, according to our theory, to the existence of scale-constants -those dimensionless constants commonly thought by physicists to be of some fundamental significance. We should therefore be able to calculate these. Here we are able to detail the calculation of one, the fine-structure constant, which Paul Dirac emphasized for much of his life as an outstanding problem in the completion of quantum electrodynamics. Our value agrees with the experimentally determined one to better than one part in $10^{5}$. The calculation of dimensionless constants will bring to mind the name of Eddington, and although his work was the original cause of the authors' meeting, and although they agree with him in seeking a combinatorial origin for these constants, their mathematical method, and certainly their calculations of the values of those, have nothing in common with his. 
This is a book about physics but philosophers will find that some issues - once their province - which they thought dead and decently buried, are resurrected to new life here. Notable amomg these is the place of mind. The great originators of the quantum theory knew that the action of the mind (or the "observer") had to be part of the theoretical structure, but this development has been aborted. In combinatorial theory there is no escape from the issue. In somewhat the same way, since computing is essentially combinatorial, people in and around computer science may find our representation of physics more natural to them than it is to some orthodox physicists. None the less it is primarily the physics community we seek to inspire to carry further a project of which this is the beginning. 


\section{Contents}

Preface v

Chapter 1 Introduction and Summary of Chapters 1

2 Space 7

3 Complementarity and All That 17

4 The Simple Case for a Combinatorial Physics 25

5 A Hierarchical Model - Some Introductory Arguments 33

6 A Hierarchical Combinatorial Model - Full Treatment 57

7 Scattering and Coupling Constants 91

8 Quantum Numbers and the Particle 121

9 Toward the Continuum 135

10 Objectivity and Subjectivity - Some 'isms'. 153

References 165

$\begin{array}{lr}\text { Name Index } & 169\end{array}$

Subject Index 173 